\title{
Capturing Professionalism In Pre-Service Education: Professionalism Tool Development and Implementation
}

\author{
BARBARA RUSSELL, MARY ANNE OWEN, ELIZABETH LEIBACH, \\ ERIC MEADERS, REBECCA B. STONE, BARBARA KRAJ
}

\begin{abstract}
Recognizing that all health professions educational programs seek to graduate students possessing characteristics embodying the nebulous concept of professionalism, educators in four imaging and radiation science programs and a clinical laboratory science program collaborated to create a measurement tool for professionalism in pre-service education. The Student Professional Behavior Evaluation Tool and the process for its development and implementation are described.
\end{abstract}

INDEX TERMS: Allied Health, Clinical Laboratory Science, Education, Health Services Evaluation, Laboratory Scientists, Laboratory Personnel, Medical Laboratory Science, Medical Technology, Nuclear Medicine, Professionalism, Radiation Therapy, Sonography, Medical Dosimetry, Radiography, Cultural Competency

Clin Lab Sci 2011;24(4):Suppl 4-11

Barbara Russell, Ed.D. MLS(ASCP $)^{C M}, S H(A S C P)^{C M}$, Georgia Health Sciences University, Augusta, GA

Mary Anne Owen, MHE, RT(N), Georgia Health Sciences University, Augusta, GA

Elizabeth Leibach, Ed.D., M.S., MLS(ASCP) $)^{C M}$, $S B B(A S C P)^{C M}$, Georgia Health Sciences University, Augusta, GA

Eric Meaders, Ed.S., RDS, RVT, Georgia Health Sciences University, Augusta, GA

Rebecca B. Stone, M.Ed., MT(ASCP), Georgia Health Sciences University, Augusta, GA
Barbara Kraj, MS, MLS(ASCP) ${ }^{C M}$, Georgia Health Sciences University, Augusta, GA

Address for Correspondence: Barbara Russell, Ed.D. $M T(A S C P)^{C M}, S H$, Department of Medical Laboratory, Imaging, and Radiologic Sciences, Georgia Health Sciences University, EC-3340, $112015^{\text {th }}$ Street, Augusta, GA 30912, (706) 721-7627, brussell@georgiahealth.edu

\section{BACKGROUND}

The mercurial concept of medical professionalism is embedded in the principle that healthcare providers have an unwritten contract with society to behave and perform in an expected manner. ${ }^{1}$ Not only do all healthcare programs seek students that possess capacity for mastery of technical competency, but in addition, they seek students with potential to internalize the caring, altruistic characteristics of mind and discipline that constitute professionalism.

Healthcare education literature defines professionalism in terms of the following constructs: humanism, reliability and responsibility; honesty and integrity; maturity; respect for others' critique; altruism; duty; caring and compassion; excellence and scholarship; leadership; interpersonal and communication skills; absence of impairment; self improvement; adaptability; accountability; autonomy and self-regulation; conflict management; and knowledge. ${ }^{2,3}$

In general, healthcare education accrediting bodies require practice-related descriptors and, increasingly, require that educational programs document delivery and mastery of professionalism concepts. ${ }^{4}$ The need for identifying professionalism characteristics and documenting mastery was evident from a seminal study finding that medical students who demonstrated 


\section{CLINICAL PRACTICE}

negative behaviors and performance related to professional presentation were more likely to be reprimanded by the Medical Board of California after they had graduated and entered medical practice. ${ }^{5}$ This occurrence and other reports of resident failure to identify personal aspects of professionalism for improvement ${ }^{1}$ are examples of experiences that have led several academic medical organizations to press forward in identifying characteristics of professionalism along with multiple mechanisms for assessment.

The American Board of Internal Medicine (ABIM), ${ }^{6}$ the Association of Academic Medical Colleges (AAMC), ${ }^{3}$ the National Board of Medical Examiners ${ }^{7}$ and the Accreditation Commission for Graduate Medical Education (ACGME) ${ }^{8}$ have all developed recommendations for medical professionalism education and assessment. Project Professionalism produced by the ABIM provides a comprehensive examination of the elements listed above with recommendations for instruction and assessment within clinical programs. $^{6}$ In addition, professionalism instruction and assessment comes in many instructional forms including direct classroom instruction, behavior observation and modeling, simulation, self-reflection and journaling. Delivery of instruction should be guided by defined behaviors that can be documented rather than by value concepts that are abstract in nature. $^{2}$

Educators in four imaging and radiation science programs and a clinical laboratory science program defined and differentiated behavioral competencies for clinicians across disciplines and developed a tool for assessment of these professionalism characteristics. This paper outlines the efforts of this group of faculty and the process they used to develop this standardized instruction and assessment tool for the evaluation of professionalism across disciplines.

\section{IMPLEMENTING CHANGE}

Six faculty members, representing all five healthcare professions in an academic department in a major medical university, i.e., clinical laboratory science, diagnostic medical sonography, nuclear medicine technology, medical dosimetry, and radiation therapy, were charged to work on this project. The project goals included both design and implementation.

Project goals were to:

4-12 VOL 24, NO 4 FALL 2011 SUPPLEMENT CLINICAL LABORATORY SCIENCE
1. define professionalism,

2. identify specific professional behaviors expected of students and ensure the presence of environments and strategies for professionalism enculturation in each discipline's curriculum,

3. develop an evaluation tool to measure student utilization of these professional behaviors, and

4. develop common course objectives linked to the desired professional behaviors and to systematically monitor and evaluate the level of students' professional behavior within each didactic and clinical course.

\section{Goal One: Define Professionalism}

Given the rich connotations of the term "professionalism," the group's first task was to fashion a definition framing the "best practices" of the five disciplines. Group members searched a variety of resources and provided suggestions which were compiled. Through a simple voting process, the group agreed upon the following definition: "habitual and judicious use of communication, knowledge, technical skills, clinical reasoning, emotions, values, and reflection in daily practice for the benefit of the individual and community being served."

Goal Two: Identification of Specific Professional Behaviors The second step was to identify observable behaviors representing the professional practices included within the selected definition of professionalism. A modified Delphi process was used to step through this task. ${ }^{10}$ Each group member was charged to develop a list of professional behaviors for consideration. Group members incorporated information from professional literature, existing evaluation tools, and personal insight from professional experience in generating the list of attributes. ${ }^{4,11,12,13,14}$ The initial list contained 55 attributes, organized into 7 categories; these are listed in Table 1.

Each group member ranked every attribute on a 5-point Likert scale, with " 1 " being essential; " 3 " being important; and " 5 " being not important. After the task, the group determined the cut-off for retention of attributes. The group consensus was that while all the attributes originally listed would be optimal for students to exhibit, those with an average score of 2.5 or lower were considered most essential to the professional development of students. The rankings were averaged 


\section{CLINICAL PRACTICE}

Table 1. Initial List of Attributes and Categories

\begin{tabular}{|c|c|}
\hline Category & Attributes \\
\hline \multirow{12}{*}{ Attitude } & Caring; compassion; empathy; warmth \\
\hline & 2. Selflessness \\
\hline & 3. Cynicism/moodiness \\
\hline & 4. Acceptance of constructive criticism \\
\hline & 5. Positive application of constructive criticism \\
\hline & 6. Pleasantness/amiability; harmony/cooperation \\
\hline & 7. Respectfulness \\
\hline & 8. Respects patient dignity \\
\hline & 9. Sensitivity \\
\hline & 10. Altruistic \\
\hline & 11. Conscientiousness \\
\hline & 12. Sincerity/genuineness \\
\hline \multirow[t]{9}{*}{ Integrity } & 13. Dependability; reliability, responsibility \\
\hline & 14. Accountability \\
\hline & 15. Honesty/deceptiveness \\
\hline & 16. Exercise of sound judgment \\
\hline & 17. Equitable sharing of workload \\
\hline & 18. Responsibility \\
\hline & 19. Ethical/personifies professional code of ethics \\
\hline & 20. Values quality of work \\
\hline & 21. Admits mistakes/apologizes as appropriate \\
\hline \multirow[t]{11}{*}{ Communication } & 22. Maintains confidentiality \\
\hline & $\begin{array}{l}\text { 23. Communicates at appropriate level for patient profile; effectiveness of listening and nonverbal } \\
\text { communication skills }\end{array}$ \\
\hline & Follows appropriate process of communicating information \\
\hline & Perceives needs of patients, co-workers \\
\hline & Relevancy of communication \\
\hline & Courtesy/politeness of communication \\
\hline & Appropriate demonstration of emotions when communicating \\
\hline & Organizational ability when communicating \\
\hline & Observance \\
\hline & Cultural sensitivity \\
\hline & 32. Conflict resolution/diplomacy \\
\hline \multirow[t]{7}{*}{ Motivation } & 33. Interest in career/professional organizations \\
\hline & $\begin{array}{l}\text { 34. Propensity toward self-development/advancement; initiative - seeks out learning opportunities as } \\
\text { appropriate }\end{array}$ \\
\hline & 35. Preparation for assignments \\
\hline & 36. Tardiness/absences \\
\hline & 37. Contributes positively to students/self/overall reputation \\
\hline & 38. Commitment to excellence/lifelong learning \\
\hline & 39. Dedication \\
\hline \multirow[t]{6}{*}{ Independence/Leadership } & 40. Conformance to authority \\
\hline & 41. Respect for authority \\
\hline & 42. Adaptability; works under pressure; deals with uncertainty \\
\hline & 43. Performance: speed, accuracy, productivity, thoroughness \\
\hline & 44. Knows when to ask questions/or for help \\
\hline & 45. Leadership skills \\
\hline \multirow[t]{5}{*}{ Self-worth/Assessment } & 46. Appearance; personal hygiene \\
\hline & 47. Self welfare vs. others' welfare \\
\hline & 48. Confidence vs .cockiness/dominance/condescension \\
\hline & 49. Recognizes limitations and strengths \\
\hline & 50. Maturity \\
\hline \multirow[t]{5}{*}{ Altruism } & 51. Importance of community service \\
\hline & 52. Desire to help others \\
\hline & 53. Importance/value of relationships \\
\hline & 54. Citizenship \\
\hline & 55. Humanism \\
\hline
\end{tabular}

for each item, and some reorganization of attributes was suggested as a result of the ranking process. Through the ranking process, twenty-one attributes were removed from the original 55 descriptors, four of the remaining original attributes were combined into two and one attribute was factored. Because it was judged that "Acceptance of Constructive Criticism" and "Positive Application of Constructive Criticism" were 


\section{CLINICAL PRACTICE}

essentially the same construct in practice, the two were combined into "Acceptance of Constructive Criticism." Likewise, "Respectfulness" and "Respects Patient Dignity" were combined into the more general category, "Respect." Because many other factors can be observed to impact appearance other than personal hygiene, the original attribute "Appearance/Personal Hygiene" was divided into the two attributes of "Appearance" and "Personal Hygiene." This left a total of 33 attributes in the final tool. The attributes that were removed, because of a score of 2.6 or above, are shown in Table 2 . Originally there were 7 categories. In the final tool the "Altruism" category was judged to be subsumed within the category of "Selfworth/Assessment," and the attributes within that category were combined with the latter. Therefore, a total of six categories remained in the final document.

\section{Goal Three: Development of an Evaluation Tool}

The next step was to develop an evaluation tool to measure the affective domain of professionalism. This evaluation tool needed to be comprehensive enough to use at specific times or in particular instances, longitudinally and in multiple settings (ex., classroom; various clinic settings; internet). Also, the evaluation was to allow for: 1) student self-assessment/reflection; 2) timely feedback and guidance from supervisors or instructors; 3) opportunities for remediation; and 4) reward and reinforcement. After weighing these elements, the group chose to develop one evaluation tool, entitled the Student Professional Behavior Evaluation Tool, that encompassed all the attributes but was intuitive and relatively quick to complete; applicable to all learning environments; included areas for feedback, guidance and remediation; contributed to every course's grade. The main intent of this tool was to provide summative results, determined by the course instructor or clinical supervisor. This evaluation would be a result of the compilation of the professional attributes that were developed and determined to be important measures of professionalism behaviors.

\section{Goal Four: Development of Common Course Objectives}

The next step was to confirm there were opportunities for professional socialization (enculturation) of the professionalism attributes within each discipline's curricula. Professional socialization is defined as "the

Table 2. List of Attributes with Scores that were removed from the Student Professional Behavior Evaluation Tool

\begin{tabular}{|c|c|c|}
\hline Category & Attributes & Likert Score \\
\hline \multirow[t]{5}{*}{ Attitude } & Selflessness & 3.0 \\
\hline & Cynicism/moodiness & 4.4 \\
\hline & 3. Pleasantness/amiability; harmony/cooperation & 2.6 \\
\hline & 4. Sensitivity & 2.6 \\
\hline & 5. Altruistic & 2.8 \\
\hline Communication & Organizational ability when communicating & 2.6 \\
\hline \multirow[t]{5}{*}{ Motivation } & 7. Interest in career/professional organizations & 2.6 \\
\hline & $\begin{array}{l}\text { 8. Propensity toward self-development/ } \\
\text { advancement; initiative - seeks out learning } \\
\text { opportunities as appropriate }\end{array}$ & 2.6 \\
\hline & $\begin{array}{l}\text { 9. Contributes positively to students/self/overall } \\
\text { reputation }\end{array}$ & 3.0 \\
\hline & 10. Commitment to excellence/lifelong learning & 2.8 \\
\hline & 11. Dedication & 2.6 \\
\hline \multirow[t]{3}{*}{ Independence/Leadership } & 12. Conformance to authority & 2.6 \\
\hline & $\begin{array}{l}\text { 13. Performance: speed, accuracy, productivity, } \\
\text { thoroughness }\end{array}$ & 3.0 \\
\hline & 14. Leadership skills & 3.6 \\
\hline \multirow[t]{3}{*}{ Self-Worth/Assessment } & 15. Self welfare vs. others' welfare & 2.6 \\
\hline & 16. Confidence vs. cockiness/dominance/condescension & 2.6 \\
\hline & 17. Maturity & 3.0 \\
\hline \multirow[t]{4}{*}{ Altruism } & 18. Importance of community service & 4.4 \\
\hline & 19. Importance/value of relationships & 3.0 \\
\hline & 20. Citizenship & 3.8 \\
\hline & 21. Humanism & 3.6 \\
\hline
\end{tabular}

${ }^{*}$ Attributes that scored a 2.6 or higher on a 5-point Likert scale were removed from the final professionalism tool. 


\section{CLINICAL PRACTICE}

process of inculcating a profession's attitude, values and behaviors in a professional." 15

This goal was accomplished by developing a grid with the attributes listed versus the coursework in a given program. Faculty reviewed each attribute and checked off in which course(s) opportunities for professional socialization of that item take place. In doing so, group members reminded themselves that this process is accomplished through a variety of strategies, including: career shadowing; open house events; recruiting events; distribution of professional literature; program orientation, discussion of expectations and policies; clinical observation and participation; modeling; selfassessment, reflection; role-playing; standardized or simulated patient encounters; videotaping performance; portfolios; small group discussion; written assignments; interviews; projects; logs, chats; gaming; award ceremonies; formal recognition of performance; traditional formal course offerings; student involvement in professional organizations; financial support for student participation in professional meetings; and community service projects.

The last step in Design Goal Four was to determine how the Student Professional Behavior Evaluation Tool would be incorporated into the curricula. The group felt strongly that the tool needed to be incorporated in all courses, which included lectures, laboratories, and clinical internship courses. In addition, the decision was made that the weighting of the professionalism evaluation should be the same across all courses in all disciplines. However, the group was divided about the total weight the professionalism grade should carry in the grading model of each course. Each group member proposed a percentage that the professionalism score should comprise of the final course grade. The suggestions ranged from $5-25 \%$. A consensus could not be met among the six members of the group, so it was decided all faculty within the department would decide the percentage.

In addition, the group needed to ensure all faculty incorporated professionalism objectives into their courses. Therefore, a student professionalism policy was developed that was to be incorporated into all course syllabi. This policy included: a preface, underscoring the importance the department places on development and exhibition of professional behavior by students; specific reference to institutional and departmental policies related to student conduct and professional behavior; and professional expectations objectives that matched the professionalism attributes developed. The objectives that were created stated that the student was expected to exhibit:

1. Attitude (which included 5 attributes),

2. Integrity (which included 9 attributes),

3. Communication (which included 10 attributes),

4. Motivation (which included 2 attributes),

5. Independence/Leadership (which included 3 attributes), and

6. Self-worth/Assessment/Altruism (which included 4 attributes).

Faculty were given the opportunity to review the Student Professional Behavior Evaluation Policy and the Tool along with a list of considerations requiring faculty decision. Refer to Table 3 for the full list of considerations. A survey was developed containing forced-choice items of the considerations based on points and e-mailed to 18 department faculty. The response rate was $33 \%$.

The committee asked in the survey: what should the weighting of the Student Professionalism Behavior Evaluation Tool be within each course, 5\%, 10\%, or other? The survey results were split between $5 \%$ and $10 \%$, so the committee made the final recommendation of $10 \%$. Another question that was decided by the faculty was whether we should keep the 5-point Likert scale that the committee had created for the evaluation of each category (exceeded expectations, met expectations, mostly met expectations, met some expectations, not met expectations), and whether a "not applicable" scale should be added, or whether the scale developed should be changed. The faculty decided that the 5-point Likert scale already developed was satisfactory but they requested that a not applicable category be added. An important question that had to be answered by the developmental group was how to weight each of the six categories. The faculty had varying opinions on how to weight the six categories so the developmental group decided which categories should carry the most weight. The group determined that the categories of attitude and integrity would carry the most weight, with each category being a total of 25 points. The categories of communication and motiva- 


\section{CLINICAL PRACTICE}

Table 3: Considerations Requiring Faculty Decision

\begin{tabular}{|c|c|}
\hline Consideration & Questions \\
\hline Ownership & $\begin{array}{l}\text { 1. Do all faculty support the need for formalizing } \\
\text { professionalism in their respective programs? }\end{array}$ \\
\hline Method & $\begin{array}{l}\text { 1. Is there a better way? } \\
\text { 2. Is there a different system that could reduce the time and } \\
\text { effort involved and still accomplish the goal? }\end{array}$ \\
\hline $\begin{array}{l}\text { Grading model } \\
\text { impact }\end{array}$ & $\begin{array}{l}\text { 1. What should the weighting of the Student Professionalism } \\
\text { Behavior Evaluation Tool be within each course be? } 5 \% \text {, } \\
10 \%, 15 \% \ldots \ldots .\end{array}$ \\
\hline \multirow[t]{2}{*}{ Breadth of applicability } & $\begin{array}{l}\text { 1. Should the tool be applied to all aspects of the curriculum, or } \\
\text { only certain areas? }\end{array}$ \\
\hline & 2. Should the tool apply to extra-curricular activities? \\
\hline \multirow[t]{2}{*}{ Content validity } & $\begin{array}{l}\text { 1. Are the attributes within the tool the items that we want to } \\
\text { evaluate? }\end{array}$ \\
\hline & 2. Are these tools appropriate for students? \\
\hline \multirow[t]{5}{*}{ Construct reliability } & 1. Evaluation of categories: \\
\hline & $\begin{array}{l}\text { a. How should each attribute be measured? Met, Partially } \\
\text { met, Not met? }\end{array}$ \\
\hline & b. Should a category "not observed" be added? \\
\hline & 2. Weighting of categories within the tool: \\
\hline & a. How much weight should each category have? \\
\hline
\end{tabular}

tion would be worth 15 points each, and the categories of independence/leadership and self-worth/assessment/ altruism were worth 10 points each. (Refer to Table 4 for the final Student Professional Behavior Evaluation Tool.)

\section{IMPLEMENTATION}

The Student Professional Behavior Evaluation Policy and Tool were implemented Fall 2006 and distributed to the students during fall orientation. It was explained to the students that it would be incorporated into all courses, it would constitute $10 \%$ of their course grade, and at the beginning of the course everyone would have a score of 100 on their Professionalism Evaluation. If infractions occurred throughout the semester, points would be taken off of students' scores by using the Tool. If a student had a serious enough infraction, showed a consistent infraction, or had numerous infractions the faculty would complete a midterm evaluation and review this with the student with the hope that the student would understand the seriousness of the infraction/s and attempt to correct the problem $/ \mathrm{s}$ so as to improve their Professionalism score.

Since implementation, the Student Professional Behavior Evaluation Tool has been used in all courses to evaluate, with the goal of improving, students' behavior. Faculty have used it to point out the positive professional attributes that students may have as well as the negative. One faculty member noted that she writes a comment on the student's evaluation emphasizing their strong points. This is one way that faculty can show students that even though they might not realize that they are being watched by colleagues as they do their work, people do notice, appreciate, and expect professional behavior.

The Student Professional Behavior Evaluation Tool has been used to assist clinical preceptors in identifying and targeting specific psycho-social behaviors for improvement and remediation during clinical rotations. Typically, clinical instructors were able to model and mentor for specific technical skills, but found it difficult to mentor for more qualitative aspects of behavior and were reluctant to discuss these behaviors with the students. By using this tool, instructors were able to provide graded evaluations of professional behavior using defined objectives rather than relying on observational subjective reporting.

The tool has been used as an ungraded assessment of professional behaviors at midterm. For example, when students are consistently late or come unprepared to laboratories, this tool can be used to point out these behaviors in a constructive manner hoping that the student will seek to improve these behaviors before the 


\section{CLINICAL PRACTICE}

Table 4. Student Professional Behavior Evaluation Tool

Student __ Evaluator __ Date:

Evaluate the following behaviors by checking the appropriate box. For any items in which a "some met" or "not met" score is given, provide at the end of this form specific comments, action taken, follow-up, and/or whether additional action is needed for that item.* This score comprises $10 \%$ of the course grade.

\section{ATTITUDE:}

Expectations: Exceeded(25)[];Met(23)[];Mostly Met(18)[];Some Met(13)[];Not Met(0)[]; N/A []

Compassion/Empathy: demonstrate calm, compassionate, helpful demeanor toward those in need; respond appropriately to the emotional response of those in which you interact; take initiative to help others with both spoken and unspoken needs, problems, issues; demonstrate empathy in professional interactions with others; be supportive and reassuring to others

Acceptance of Constructive Criticism: receive constructive criticism with a positive attitude and use feedback to improve his behavior/performance; provide constructive criticism in a positive manner so it will be received by others in a productive way

Respect: treat others with dignity and respect; refrain from generating or spreading gossip, profanity, demeaning, foul, threatening, abusive or other negative communication; behave in a manner that brings credit to his school, discipline, and employer; avoid criticism of people in front of others; treat equipment and other resources with due care

Conscientiousness: be meticulous and careful in conducting professional tasks; consistently strive for excellence in professional activities

Sincerity/Genuineness: demonstrate authentic expression/communication by appropriate use of voice tone, volume and inflection; avoid use of patronizing terms (sweetie, honey, etc.) and impersonal communication; recognize a job well done by others

\section{INTEGRITY:}

Expectations: Exceeded(25)[];Met(23)[];Mostly Met(18)[];Some Met(13)[];Not Met(0)[]; N/A []

Dependability/Reliability: be dependable in all professional dealings; honor his commitments

Accountability: be accountable for his actions and their consequences

Honesty: be consistently truthful, forthright, fair, and credible; be trustworthy by those with whom he interacts; be trusted with the property of others; refrain from deceptive practices; avoid being placed in a compromising situation, either directly or by association; report actions deemed dishonest, illegal, or unethical to the proper authorities for action

Exercise of Sound Judgment: make sound decisions based upon established rules and regulations, fact, and logic

Workload Sharing/Teamwork: show proper respect for group members; work cooperatively with others; actively participate in group work from beginning to completion; contribute his share when working as a group (in number and complexity of tasks); if his assignment is complete, seek out opportunities to contribute above and beyond minimum requirement; value the knowledge, expertise and suggestions of group members; communicate with other group members to resolve problems; participate in group discussion without attempt to dominate; put the success of the group above self-interest; be willing to mentor those in need of encouragement and direction

Responsibility: be competent before performing a task independently; without request, take on and follow through with tasks; demonstrate self-reliance in carrying out professional tasks; provide realistic time estimates for completion of specific tasks; insure tasks within his responsibility are completed fully and in a timely manner; act with the safety of yourself and others in mind; look out for the well-being of others

Demonstration of Professional Code of Ethics: be intimately familiar with his discipline's Code of Ethics and potential consequences of noncompliance; demonstrate a high standard in personal and professional behavior; report violations of the Professional Code of Ethics to the proper authorities for action

Quality of Work: set a high standard for quality of professional expertise and outcomes; excel in productive use of time and resources; choose to perform tasks according to proper protocols rather than taking "shortcuts"; remain abreast of new information in your professional discipline and health care in general

Admission of Mistakes: acknowledge mistakes/errors, apologize and amend appropriately

\section{COMMUNICATION:}

Expectations: Exceeded(15)[];Met(13)[];Mostly Met(10)[];Some $\operatorname{Met}(7)[$ ];Not $\operatorname{Met}(0)[] ;$ N/A []

Confidentiality: protect and preserve personal confidential information of others to which you may have access; observe appropriate conversational etiquette in various professional settings (elevators, cafeteria, work area, offices, classrooms, hallways, etc.)

Level/Quality of Communication: create comfortable communicative atmosphere; communicate with volume, tone, terminology, and nonverbal cues appropriate to the situation presented; convey written messages appropriately; provide appropriate information to others that will assist them with tasks/procedures at hand; listen actively and confirm accuracy of interpretation of communication; adjust communication strategies to fit various situations; encourage questions to clarify information; use humor appropriately in communications

Communication Process: follow established rules and regulations regarding hierarchy of communication; communicate in a timely manner Perception of Others' Needs: be attentive to the needs of others

Relevancy of Communication: refrain from personal activities while in professional environment; demonstrate proper discernment re: content of professional communications (ex. interactions are relevant, appropriate, respectful) 


\section{CLINICAL PRACTICE}

Table 4. (continued)

Politeness: respond to others in a positive manner by smiling and speaking with a genuine tone; display appropriate manners in interacting with others (ex. use appropriate surnames and titles in formal/professional interactions; identify yourself and your role when communicating with others; allow patients, elders, etc. priority in entering and exiting buildings and elevators); avoid interrupting speaker

Emotional Control: demonstrate appropriate physical, verbal, and emotional restraint in professional interactions with others

Observance: anticipate needs of others based on physical, verbal and nonverbal cues

Cultural Sensitivity: demonstrate understanding of cultural, religious, and spiritual differences of others; exhibit appropriate sensitivity in interactions with those of different cultures, religions, and spiritualities

Conflict Resolution/Diplomacy: use tact when presented with (potentially) volatile situations; follow appropriate protocol in resolution of conflict; exhibit proper restraint in communication during conflict resolution

\section{MOTIVATION:}

Expectations: Exceeded(15)[];Met(13)[];Mostly Met(10)[];Some Met(7)[];Not Met(0)[]; N/A []

Preparation for assignments: organize information appropriately for use/study; bring prior assigned materials with him to designated activities; put forth genuine effort to prepare for, and complete, assignments; use outside resources in addition to required texts to research relevant information; demonstrate both quantity and quality of effort in completing assignments; fully complete assignments by their deadlines

Attendance: be early or on time for all activities even when attendance is optional; if unavoidably late or absent, contact appropriate party ahead of time, or as soon as reasonably possible in an emergency, to inform him of change in arrival time; in the event of absence, take responsibility for getting information missed and requesting rescheduling of activities, if appropriate/allowed

\section{INDEPENDENCE/LEADERSHIP:}

Expectations: Exceeded(10)[];Met(9)[];Mostly Met(7)[];Some Met(5)[];Not Met(0)[]; N/A []

Respect for authority: understand R\&R of unit of which you're a part; comply with established R\&R in task completion; champion and communicate the mission and vision of your school, employer, profession; uses grievance mechanisms appropriately

Adaptability: be flexible in dealing with issues that are not absolute in nature; appropriately modify and reorganize rules and regulations/ protocols as needed; adapt to different instructors or modes of instructions; accept changes in assignments and schedules without flustering

Understanding of Limitations: do not attempt tasks beyond your capabilities without instructor/supervisor's consent

\section{SELF-WORTH/ASSESSMENT/ALTRUISM:}

\section{Expectations: Exceeded(10)[];Met(9)[];Mostly $\operatorname{Met}(7)[$ ];Some $\operatorname{Met}(5)[] ; \operatorname{Not} \operatorname{Met}(0)[] ;$ N/A []}

Appearance: meet or exceed standards for professional dress

Personal Hygiene: meet or exceed standards for professional grooming

Recognition of Strengths/Weaknesses: use feedback from other professionals, peers, and self-reflection to identify strengths

and weaknesses; proactively look for ways to improve your behavior and performance; value the positive contributions you make to your school, discipline, and employer

Desire to Help Others: appreciate and recognize others for their contributions; be an advocate for those you serve; be involved in activities that improve your community and/or other groups you desire to help

* Specific comments, action taken, follow-up, and/or whether additional action is needed for an item (identify the item \# to which you are referring; use back of page if more space needed):

Score (pts):

I. $-\square$
II. -
III. -
IV. -
V. -
VI.

Total Score:

Comments:

end of the semester. In positive cases, behavior has improved. In negative cases, the professionalism grade became documentation for dismissal of students who could not perform appropriately within a clinical setting, despite meeting technical competency requirements. 


\section{CLINICAL PRACTICE}

\section{DISCUSSION}

Faculty are comfortable with evaluating the cognitive and psychomotor clinical skills of their students. However, affective skills or professional skills can be difficult to evaluate. In addition, poor professional behaviors can be difficult to communicate to students in constructive and meaningful ways. Researchers have shown that professionalism is an important component of medical education. In addition, researchers found that students who exhibited unprofessional behavior during medical school were at higher risk for disciplinary action later during professional practice. For this reason, the researchers recommended that standardized instruments be developed to evaluate professional behavior and to document deficiencies. ${ }^{5}$ Standardized tools for the evaluation of professional behavior give faculty a way to provide objective feedback to students who exhibit substandard professional behavior. Early detection and intervention would hopefully lead to better behavior in the educational setting which would ultimately lead to a professional clinician.

Given the multicultural healthcare environment, the development of tools for the evaluation of professional behavior is a daunting task. However, professional behavior cannot be ignored in healthcare education because of the causal link to professional behaviors in practice. The authors have described a process in which faculty developed a standardized tool to measure professional behavior across five healthcare disciplines. While all faculty in the department felt strongly that a tool was needed, there were in-depth discussions on descriptors and nuances of items to be measured, construction, and implementation of the tool in the grading model didactic, student laboratory, and clinical courses.

There were concerns regarding how effectively the tool could be used by the academic and clinical faculty. Some of the concerns were:

1. the tool could be too cumbersome and faculty would not incorporate the tool into their courses,

2. clinical faculty would not take the time to use the tool the way it was intended to be used,

3. professionalism could not be measured objectively,
4. $10 \%$ overall was too high of a course percentage.

The committee was not sure if these concerns would actually be realized and was unsure how to address these issues without constructive feedback. For this reason, the committee decided to proceed with the implementation and collect feedback. Since implementation, faculty have used the Student Professional Behavior Evaluation Tool in all courses. Neither didactic nor clinical faculty have expressed concern over the tool being too cumbersome. Nor have they stated that professionalism could not be measured objectively. Even though the strongest concern expressed by faculty before implementation was weighting of the Professionalism grade at $10 \%$ of the final grade, no faculty have expressed a desire to change this percentage.

\section{CONCLUSION}

The design of the professionalism attributes tool resulted from a need to address and measure students' professionalism across multiple allied health disciplines. The goals of this project were to: define professionalism; identify specific professional behaviors expected of students and ensure the presence of environments and strategies for professionalism enculturation in each discipline's curriculum; develop an evaluation tool to measure student utilization of these professional behaviors; and develop common course objectives linked to the desired professional behaviors and to systematically monitor and evaluate the level of students' professional behavior within each didactic and clinical course.

The authors, representing five allied health professions, defined professionalism, generated a list of attributes, and identified a list of specific behavioral professional expectations. The group then focused on the evaluation of the expectations and tool development. Common course objectives were designed and specifically linked to the Student Professional Behavior Evaluation Tool, professionalism was incorporated into all courses, and weighted at $10 \%$ of the final grade. Implementation occurred in 2006 and since then it has been used in all courses across the imaging and radiation science and in clinical laboratory science. All faculty have used the tool, have identified both positive and problematic student behaviors, and have used it to address remediation with students. 


\section{CLINICAL PRACTICE}

As discovered by the authors, this project was a formidable task because of the multifaceted connotations of professionalism and challenge this presents in teaching and evaluation. Future research that identifies what motivates students to change professional behavior would be helpful. Such studies could identify specific elements that are associated with both positive and negative outcomes. Further investigation regarding how faculty employ professional attributes tool is also needed. Such knowledge will provide significant insight not only as to what degree faculty genuinely value this aspect of professional development, but also whether they are truly willing to spend the time and effort necessary to adequately foster and evaluate students' professionalism.

\section{REFERENCES}

1. Sax HC. Medical Professionalism in the new millennium: a physician charter. Ann Intern Med. 2002;136(3):243-6.

2. Arnold L. Assessing professional behavior: yesterday, today, and tomorrow. Acad Med. 2002;77(6):502-15.

3. Association of American Medical Colleges; National Board of Medical Examiners. Embedding Professionalism in medical education: assessment as a tool for implementation. 2002. Available from: http://www.nbme.org/pdf/nbme_aamc_profess report.pdf Accessed April 1, 2011.

4, Joint Review Committee on Educational Programs in Nuclear Medicine Technology. Essentials and guidelines for an accredited educational program for the nuclear medicine technologist. 2003. Available from: http://www.jrcnmt.org/ pdf/2003\%20Essentials.pdf Accessed April 1, 2011.

5. Papadakis M, Teherani A, Banach M, Knettler T, Rattner S, Stern D, et al. Disciplinary action by medical boards and prior behavior in medical school. N Engl J Med. 2005;353(25): 2673-82.
6. American Board of Internal Medicine. Project professionalism. 7th printing. 2001. Available from: http://www.abim foundation.org/Resource\%20Center/Bibliography/ /media/Fil es/Resource\%20Center/Project\%20professionalism.ashx Accessed April 1, 2011

7. National Board of Medical Examiners. Assessment of professional behaviors program (APB). Available: http://www. nbme.org/Schools/APB/index.html Accessed April 1, 2011.

8. Accreditation Commissions for Graduate Medical Education. Advancing education in medical professionalism. 2004. Available: http://www.acgme.org/outcome/implement/profm_ resource.pdf Accessed March 1, 2010.

9. Epstein R, Hundert E. Defining and assessing professional competence. JAMA. 2002;287:226-35.

10. Boberg AL, Morris SA. The Delphi method: a review of methodology and an application in the evaluation of a higher education program. The Canadian Evaluation Society. 1992, 7(1):27-39.

11. Kenimer E. The identification and description of critical thinking behaviors in the practice of clinical laboratory science, part 1: design, implementation, and evaluation of a national survey. J Allied Health. 2002;31(2):56-63.

12. Society of Diagnostic Medical Sonography. Code of ethics for the profession of Diagnostic Medical Sonography. 2006. Available from: http://www.sdms.org/about/codeofethics.asp Accessed April 1, 2011.

13. American Society for Clinical Laboratory Science. ASCLS code of ethics. Available from: http://www.ascls.org/?page=Code Accessed April 1, 2011.

14. American Society of Radiologic Technologists. Practice standards for medical imaging and radiation therapy. Available from: http://www.asrt.org/content/RTs/PracticeStandards/ Practice_Standards.aspx Accessed April 1, 2011.

15. APhA-ASP/AACP-COD Task Force on Professionalism. White paper on pharmacy student professionalism. J Am Pharm Assoc. 2000;40:96-102.

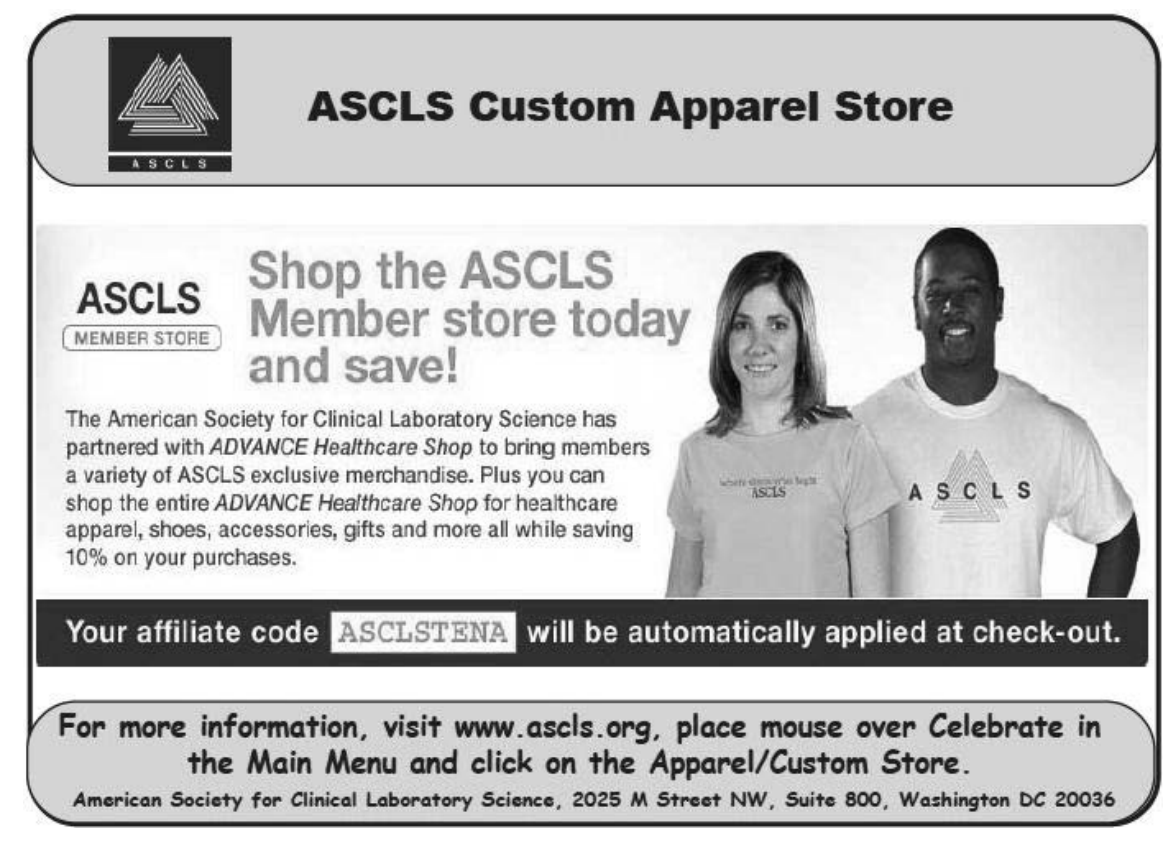

